\title{
Methylphenidate - An Antidementia? An experience report
}

\author{
Lothar Markus* \\ Specialist in General medicine, physical therapy, Johannishöhe 26 - 04279 Leipzig, Germany
}

Methylphenidate has been used for years to treat ADHD, preferably in children but increasingly also in adults. The drug requires strict indication and control when used. Since an increase in mental performance, concentration and alertness can be demonstrated, especially in adults, Ritalin was used in 3 patients aged 84, 87, 90 years with dementia symptoms and showed a very good effect. Use in this indication should be examined.

Methylphenidate is a substance belonging to the group of phenylethylamines. Although it is structurally similar to amphetamines, it is counted among the derivatives of piperidine. The Basel chemist Leandro Panizzon is considered to have discovered methylphenidate in 1937. Panizzon was 37 years old at the time of discovery and an employee of the Swiss pharmaceutical company Ciba. As was customary at the time, Panizzon first tested the new active ingredient on himself, but without feeling any particular effect, then on his wife Marguerite, who stated that she had experienced increased concentration and performance while playing tennis. In reference to the nickname of his wife "Rita", he called the new substance Ritalin. In 1950 Panizzon and Max Hartmann patented an improved manufacturing process in the USA, and in 1954 it was patented by the Swiss pharmaceutical company Ciba under the trade name "Ritalin" as a treatment for psychiatric disorders. In 1955, Ritalin was presented and approved for the treatment of numerous indications, including depression, fatigue, and narcolepsy. In 1957 it was launched in Europe [1-5].

The preparation was not very successful at the beginning. Children and adolescents with behavioral disorders have been treated with psychostimulants such as amphetamines since 1937, but only since the precise definition of ADHD (Attention Deficit Hyperactivity Disorder) as an independent disease in the 1980s and the therapeutic use of Ritalin has there been a massive increase in sales of $34 \mathrm{~kg}$ per year 1993 to $1,791 \mathrm{~kg}$ in 2011 [6-10].

The main indication area for methylphenidate is ADHD, both in children and adolescents, but increasingly also in adults. It can be used in children from the age of 6 . Strict indications are required for use, which is particularly true for therapy in children, and accompanying psycho-social treatment must always be provided. Since the drug is prescribed for months and sometimes years and the psycho-social consequences, especially in children, cannot be definitively foreseen, the need for further prescriptions should be checked again and again. However, significant organic damage to the preparation has not yet been demonstrated.

Due to its proven very good effect on cognitive performance such as concentration and attention, the substance has also been traded as a so-called "smart drug" for strengthening cognitive performance for the last $10-20$ years. The application is particularly widespread among students but also high school graduates, so that one already speaks of a "Ritalin high school diploma" [11-15].

Methylphenidate thus enjoys the reputation of a "mental doping agent" and there is now a dispute whether such a substance should not be used for this purpose should forbid, as an unnatural increase in performance and thus performance success is achieved. Since the side effect profile in terms of physical damage cannot be proven, the mental performance increase is perceived as extremely positive by the user, as it leads to better grades, passed exams and certificates and, of course, to higher social recognition. These "feelings of achievement" are undoubtedly also a stimulating factor that leads to repeated use. Because who doesn't want to be successful in life ?? !!

In contrast to other amphetamines, the substance methylphenidate, when taken correctly at a dose of 1-2 x 20 to a maximum of $2 \times 40 \mathrm{mg}$ per day in adults, hardly causes any vegetative side effects such as restlessness, sleep disorders or palpitations, but almost exclusively produces the desired increase of cognitive skills such as concentration, attention and memory. For this purpose, I occasionally used methylphenidate with students who, for various reasons, had problems successfully preparing for an exam or who had already failed. For this purpose, the drug was privately ordained as a Btm regulation and the person concerned was clearly informed of its use and its conditional and limited use. The experiences were consistently positive and I could count on happy thanks for passing exams.

Based on these positive experiences regarding the increase in cognitive performance, I have used the drug in patients with dementia symptoms such as impaired memory, concentration and drive. Here, too, it was only possible to prescribe a private prescription, which unfortunately restricted patients to a broader prescription for cost reasons. In addition, some patients had reservations when they heard that the drug was an "addictive / narcotic" drug. As a result, I can only report on 3 cases, an 84 year old, an 87 year old and a 90 year old patient with a dose of 10-20 mg Ritalin 1-2 times a day, in the morning and / or at noon. All three reported significant improvements in concentration, alertness, memory, and drive after taking the drug. This is how the 90 -year-old patient, a former opera singer, took it when she left the house to go shopping or had other mandatory appointments where she

*Correspondence to: Lothar Markus, MD, Specialist in General medicine, physical therapy, Johannishöhe 26 - 04279 Leipzig, Germany, E-mail: dr_ lothar_markus@web.de

Received: October 06, 2020; Accepted: October 12, 2020; Published: October 14,2020 
always had to be concentrated and attentive. The drug was not taken regularly by the patients, but mainly when needed, whereby the costs played a limiting role.

All three patients described to me a significant improvement in attention, concentration, drive and performance and thus an increased feeling of security in life. Negative phenomena were not observed. I consider the use of methylphenidate in patients with dementia symptoms to be recommended and would like to recommend further observations and studies [16-19].

\section{References}

1. Michael Schulte (2004) Methylphenidate (German) Paperback

2. Michael Huss (2002) Medication and ADD: use in a targeted manner - provide comprehensive support - discontinue according to plan.

3. Krause J, Krause KH (2014) ADHS im Erwachsenenalter.

4. Gerlach M (2016) Neuro-/Neuro- / psychotropic drugs in childhood and adolescence. Medicine \& Health Profession 296: 300-308.

5. Volkow ND, Wang GJ, Fowler JS, Fischman M, Foltin R, et al. (1999) Methylphenidate and cocaine have a similar in vivo potency to block dopamine transporters in the human brain. Life Sci 65: PL7-PL12. [Crossref]

6. https://compendium.ch/product/1128496-ritalin-la-kaps-10-mg/mpro

7. AWMF (2010) Deutsche Gesellschaft für Kinder- und Jugendpsychiatrie und -psychotherapie, auf den Seiten der Arbeitsgemeinschaft der Wissenschaftlichen Medizinischen Fachgesellschaften.
8. Wissenschaftliche Schlussfolgerungen und Begründung der EMEA für die Änderung der Zusammenfassung der Merkmale des Arzneimittels und der Packungsbeilage) (2018) Anhang II zur Entscheidung der Europäischen Kommission 27: 12.

9. Medicines Directive / Annex III number 44 (stimulants) (2010) Drug Regulation restrictions and exclusions (III) Medicines Directive, GBA 181: 3975.

10. Tragende Gründe (2010) The changes in the drug approval of stimulants for use in hyperkinetic disorders or attention deficit / hyperactivity disorder (ADD / ADHD) are reproduced in relation to the regulation in Annex III number 44.

11. National Association of Statutory Health Insurance Physicians (2010) Resolution of the Federal Joint Committee on an amendment to the Drugs Directive: Annex III number 44 Stimulants.

12. BfArM (2013) Methylphenidate for adults too: BfArM extends approval Methylphenidat auch für Erwachsene: BfArM erweitert Zulassung.

13. https://www.pharmazeutische-zeitung.de/2011-04/methylphenidat-zulassung-auferwachsene-ausgeweitet/

14. Man KK, Coghill D (2017) Association of Risk of Suicide Attempts with Methylphenidate Treatment. JAMA psychiatry 10: 1048-1055. [Crossref]

15. ADHS (2005) Therapie verringert die Suchtneigung. In: Ärzte-Zeitung.

16. Matthias Bastigkeit (2006) Medikamentenmissbrauch: Auf Droge durch Arzneimittel In: Pharmazeutische Zeitung.

17. Ritalin (2018) In: Drogenlexikon, drugcom.de, ein Projekt der Bundeszentrale für gesundheitliche Aufklärung, abgerufen.

18. Guilherme Finger, Emerson Rodrigues da Silva, Asdrubal Falavigna (2013) Use of methylphenidate among medical students: a systematic review. Rev Assoc Med Bras 59: 285-289. [Crossref]

19. Anlage III des Betäubungsmittelgesetzes (BtMG).

Copyright: (C2020 Markus L. This is an open-access article distributed under the terms of the Creative Commons Attribution License, which permits unrestricted use, distribution, and reproduction in any medium, provided the original author and source are credited. 